\title{
CONCEITOS ATUAIS DA PSICOPATOLOGIA DO SUICÍDIO
}

\author{
Telmo Ferreira \\ Professor de Medicina Legal da Facul- \\ dade de Medicina de Santa Maria, da \\ Universidade do Estado do Rio Grande \\ do Sul
}

A estatística dos suicídios em diversos países e regiões permitiu focalizar diferentes aspectos relacionados ao número de homens e mulheres que se suicidam, às idades em que êle mais ocorre, às raças, às condições sociais, etc.

A literatura médico-legal, entretanto é omissa quanto às causas psicológicas profundas que levam o indivíduo ao suicídio.

- Que mecanismo psicológico será êste que leva o indivíduo a vencer seu inato desejo de viver, substituindo-o pelo desejo da morte?

E objetivo dêste, fazer uma exposição breve das motivações inconscientes do suicídio, valendo-se da literatura psiquiátrica e psicanalítica. Utilizamos para sua elaboração, bàsicamente, a obra de ANGEL GARMA: "Sadismo e masoquismo en la conducta humana".

Partindo da idéia de que o suicídio ocorre em conseqüência de um estado psíquico patológico, verifica-se que é na melancolia onde se encontra o maior perigo do suicídio.

Um estado depressivo intenso é devido à perda da autoestima, assim como, à perda de objetos libidinosos; o abandono ou morte de uma pessoa amada.

$\mathrm{Na}$ melancolia encontramos um estado psíquico doloroso, 
no qual ocorre uma ausência de interêsse pelo mundo exterior, a perda da capacidade de amar, a diminuição de tôdas as funções orgânicas e a redução de seu amor-próprio. Esta última determina uma série de acusações a si mesmo, o que pode levar o indivíduo ao suicídio a fim de buscar na morte um castigo para as suas múltiplas culpas.

Segundo BLEULER, "as idéias delirantes não faltam em nenhum caso palpável de melancolia e tomam a forma da ruína econômica, corporal e psíquica".

FREUD demonstrou que as auto-acusações do melancólico são na verdade acusações que êle faz a um objeto por êle introjetado e que passou, assim, a fazer parte de seu ego, donde resulta que, quando o melancólico agride a si mesmo, realmente êle está agredindo a um objeto exterior. Assim: "A mulher que tem pena de seu marido por achar-se êle ligado a um ser tão inútil como ela, reprova, na realidade, a inutilidade do marido, qualquer que seja o sentido que ela dê a essa palavra. Não podemos estranhar que entre estas acusações correspondentes a outra pessoa e voltadas contra o ego, existam algumas referentes realmente ao próprio ego, acusações estas cuja missão é encobrir as restantes e dificultar o conhecimento da verdadeira situação".

A psicanálise da melancolia mostra como é possível ao ego consentir em sua própria destruição. A introjeção do objeto libidinoso, passando a fazer parte do ego, com sua ambivalência de amor e ódio, torna possível ao ego tratar a si mesmo como a um objeto, podendo assim dirigir contra si próprio tôda sua agressividade primitiva contra o mundo exterior. $\mathrm{O}$ objeto introjetado torna-se mais poderoso que o próprio ego, possibilitando assim a destruição dêste.

No luto, temos uma situação psicológica muito semelhante à da melancolia. Neste estado surge a tristeza, sendo recordadas situações felizes vividas e qualidades do ser amado perdido. Diminui o interêsse pela vida, as atividades se processam mecânicamente, com abolição total do entusiasmo de seu processamento e surgem manifestações de auto-agressividade, tal como rasgar vestes, arrancar cabelos, etc.

$\mathrm{Na}$ evolução normal do luto, a intensidade das cargas 
um mal cuja continuidade é assegurada através da absoluta falta de precauções para evitá-lo.

Desde que não é possível, dadas as condições em que se encontra o interior brasileiro, convocar para a magistratura apenas jurisconsultos de escol, como sucede na Inglaterra, (12) é de todo interêsse que sejam voltadas as atenções dos juris-tas e legisladores para o material humano com que é possível contar, proporcionando a essa matéria prima a necessária lapidação através de cursos de formatura e aperfeiçoamento, ou, no mínimo, apenas dêstes na impossibilidade de estabelecer também aquêles, como tentativa de dar ao problema uma solução condizente com a sua inegável transcendência.

A maneira correta de equacionar-se a dificuldade está em submeter-se o candidato a juiz a dois estágios iniciais.

O primeiro concretizado num curso teórico sistematizado através do qual lhe sejam ministrados conhecimentos particularizados sôbre as tarefas que irão constituir a sua incumbência. Isto se pode fazer até mesmo nas próprias Universidades, ou Faculdades de Direito isoladas, em cursos de especialização para pós-graduados, cujo certificado de habilitação autorize o portador a inscrever-se no concurso para juiz substituto. Apenas para exemplificar, tenha-se em conta que há disciplinas indispensáveis à formação cultural do juiz que não participam do currículo escolar das Faculdades de Direito, como Criminologia, Psicologia e Direito Tributário. Tais cursos específicos substituem com proveito o arcaico e ineficiente Doutorado, que ainda onera infrutìferamente os orçamentos universitários.

O segundo estágio, após investido nas funções de juiz substituto o candidato, deverá processar-se, a igual do que se propõem fazer os paulistas, na própria magistratura e sob a supervisão de um juiz titular.

Ademais é necessário que, da mesma forma como se exige para os militares, sejam fornecidos aos juízes, no decorrer da carreira, cursos de aperfeiçoamento indispensáveis na verdade à atualização de seus conhecimentos profissionais.

(12) - Veja-se a respeito o que diz CARLOS MaXimiliano, Hermenêutica e Aplicação do Direito, 5.a edição, pg. 89 , nota n. 70 . 
afetivas vai a pouco e pouco diminuindo, permitindo uma boa elaboração da perda do objeto.

Porém, em casos em que o luto desencadeia a melancolia, verifica-se que aquelas cargas afetivas fazem com que, numa identificação com o objeto libidinoso perdido e, pela impossibilidade de recuperar tal objeto, o indivíduo procure também a morte e, às vêzes, o mesmo tipo de morte que teve o ser amado.

Pode também o luto derivar para uma neurose obsessiva na qual o suicídio é, entretanto, mais raro. Êste estado patológico seria determinado pelo sentimento de culpa originado pela morte do ser amado, a qual, por ambivalência seria inconscientemente desejada. A menor freqüência do suicídio nesta enfermidade psíquica poderia ser explicada pelo fato de que o obsessivo consegue expressar tanta agressividade contra os objetos, que não necessita destruir a si mesmo.

GARMA distingue dois tipos de estados depressivos que chama de "depressão psicógena" e de "depressão endógena".

No primeiro, aceita a existência de um sentimento de culpa, em conseqüência do qual a agressividade do indivíduo dirige-se contra si mesmo. Êstes sentimentos de culpa impedem que as agressões do mundo exterior provoquem nêle a ação positiva de repelí-las efetivamente e fazem com que, ao contrário, êle aumente as acusações contra si próprio. Assim, se tal indivíduo chega ao suicídio, isto significa que seus sentimentos agressivos ao mundo exterior voltaram-se contra si próprio.

A melancolia (depressão) endógena encontra sua psicologia na ambivalência do próprio indivíduo. Esta ocasiona conflitos, os quais acarretam a perda do objeto libidinoso, vivenciada como uma agressão do mundo exterior.

Em ambos os casos de depressão, a impossibilidade de realizar a agressão determinaria a volta da agressão contra si mesmo, ocasionando o suicídio.

Ilustra GARMA esta concepção com o relato de um caso de um seu paciente, o qual, fantasiando, diz: "Sou capaz de levar a mulher, por quem estou apaixonado, à cama do ho- 
mem que a deseja e logo suicidar-me". Trata-se de um doente cuja neurose lhe impede satisfazer o ódio que lhe desperta àquele homem. Êste ódio, impossível de ser realizado, voltase contra êle, originando a fantasia do suicídio.

Quando a agressividade do mundo exterior diminui, diminuem, também, proporcionalmente os desejos de suicídio. No início dêste trabalho, referimo-nos a elementos estatísticos. Pois bem, tais elementos falam a favor da proporcionalidade da relação agressão exterior-suicídio. Assim, os homens casados se suicidam menos que os solteiros; quanto maior o número de filhos, tanto menor o número de suicídios; na guerra, onde há um ideal coletivo, o número de suicídios é menor, porém na derrota os suicídios aumentam.

A morte para o suicida não representa a negação total da vida, por mais ilógico que isto pareça.

Paradoxalmente, a morte pode ter para o suicida a significação de uma liberação para uma vida nova e ideal, sem as agressões do mundo exterior. É o caso dos amantes, que contrariados e impedidos de realizar seu amor, buscam no suicídio uma felicidade eterna.

Como o assinala FENICHEL "o suicídio se leva a cabo porque as esperanças ou ilusões de uma tranquilizadora gratificação se acham vinculadas a idéia de suicídio. As análises de tentativas de suicídio demonstram realmente, com freqüência, que se estabeleceu uma vinculação entre a idéia de estar morto ou de morrer e certas fantasias agradáveis e cheias de esperanças".

KAUDERS, citado por GARMA, diz: "No suicídio não podemos ver mais que uma fuga da vida. Dito com outras palavras: os motivos do suicídio, não são dados pela morte nem pelo pensamento da morte, porém pela própria vida". dentro desta concepção do significado da morte para o suicida, que surge um outro aspecto da psicopatologia do suicídio: E a agressividade do suicida contra o mundo exterior.

Com sua morte tenciona êle influir no meio ambiente, a fim de obter para si os afetos e gratificações que antes lhe foram negados.

As fantasias das crianças que dizem, dirigindo-se a seus 
pais: "Quando eu morrer, vocês se arrependerão do que me fizeram e me amarão", exemplifica a assertiva.

O suicida sabe que sua morte impedirá a continuação da agressão à sua pessoa e, ao mesmo tempo, êle agride ao mundo exterior com a sua morte, pois esta irá significar uma acusação e tôda sua reprovação ao meio ambiente. Pretende, assim, livre de agressões, continuar a permanecer lembrado em seu ambiente e talvez influir poderosamente em decisões e orientações que êle pretendeu realizar em vida. Freqüentemente, deixam cartas para melhor exercer sua influência. A greve da fome, tantas vêzes usada, é uma tentativa de suicídio com o mesmo sentido e objetivo.

Do mesmo modo pode também o suicídio representar um meio de recuperação do objeto libidinoso, como o exemplifica o suicídio do homem que se mata, quando morre sua mulher, para assim viver eternamente com ela.

Cabe aqui breve referência ao significado simbólico do meio usado para o suicídio, pelo qual o suicida pretende recuperar um objeto perdido. A morte pelo fogo, por exemplo, representaria um desejo de recuperar a pureza perdida.

O suicídio enquadra-se, também, na "série complementar" de FREUD, na relação de vivências infantis e conflitos atuais. Quando existem motivos infantis que ocasionam uma deformação da personalidade, os conflitos atuais agem com maior intensidade.

Para terminar, resta dizer que, do mesmo modo que as vivências infantis, a constituição hereditária deverá influir na psicogênese do suicídio, como ato psicopatológico que é, porém, o maior papel deverá ser desempenhado pela identificação com o objeto perdido, não sendo estranho, também, a existência de sentimentos de culpa devidos a desejos de morte daquele ou daqueles que antes se suicidaram.

Estão aqui, assim, consubstanciados os conceitos atuais da psicopatologia do suicídio, visto sob o aspecto de sua psicogênese profunda. 